Article

\title{
Bioactivities of Centaurium erythraea (Gentianaceae) Decoctions: Antioxidant Activity, Enzyme Inhibition and Docking Studies
}

\author{
Laura Guedes ${ }^{1}$, Pedro B. P. S. Reis ${ }^{2}$, Miguel Machuqueiro ${ }^{2}$, Asma Ressaissi ${ }^{1}$, Rita Pacheco ${ }^{1,3}$ \\ and Maria Luísa Serralheiro 1,4,* \\ 1 Faculty of Sciences, BioISI-Biosystems \& Integrative Sciences Institute, University of Lisbon, \\ 1649-004 Lisboa, Portugal; lrguedes@fc.ul.pt (L.G.); aressaissi@fc.ul.pt (A.R.); rpacheco@deq.isel.ipl.pt (R.P.) \\ 2 Faculty of Sciences, CQB-Centre of Chemistry and Biochemistry, University of Lisbon, 1649-004 Lisboa, \\ Portugal; pdreis@ciencias.ulisboa.pt (P.B.P.S.R.); machuque@ciencias.ulisboa.pt (M.M.) \\ 3 Área Departamental de Engenharia Química, Instituto Superior de Engenharia de Lisboa, Av. Conselheiro \\ Emídio Navarro, 1959-007 Lisboa, Portugal \\ 4 Faculty of Sciences, Departamento de Química e Bioquímica, University of Lisbon, Campo Grande, \\ 1749-016 Lisboa, Portugal \\ * Correspondence: mlserralheiro@fc.ul.pt; Tel.: +351-21-7500935
}

Received: 17 September 2019; Accepted: 21 October 2019; Published: 22 October 2019

\begin{abstract}
Centaurium erythraea is recommended for the treatment of gastrointestinal disorders and to reduce hypercholesterolemia in ethno-medicinal practice. To perform a top-down study that could give some insight into the molecular basis of these bioactivities, decoctions from C. erythraea leaves were prepared and the compounds were identified by liquid chromatography-high resolution tandem mass spectrometry (LC-MS/MS). Secoiridoids glycosides, like gentiopicroside and sweroside, and several xanthones, such as di-hydroxy-dimethoxyxanthone, were identified. Following some of the bioactivities previously ascribed to $C$. erythraea, we have studied its antioxidant capacity and the ability to inhibit acetylcholinesterase (AChE) and 3-hydroxy-3-methylglutaryl coenzyme A reductase (HMGR). Significant antioxidant activities were observed, following three assays: free radical 2,2-diphenyl-1-picrylhydrazyl (DPPH) reduction; lipoperoxidation; and NO radical scavenging capacity. The AChE and HMGR inhibitory activities for the decoction were also measured (56\% at $500 \mu \mathrm{g} / \mathrm{mL}$ and $48 \%$ at $10 \mu \mathrm{g} / \mathrm{mL}$, respectively). Molecular docking studies indicated that xanthones are better AChE inhibitors than gentiopicroside, while this compound exhibits a better shape complementarity with the HMGR active site than xanthones. To the extent of our knowledge, this is the first report on AChE and HMGR activities by C. erythraea decoctions, in a top-down analysis, complemented with in silico molecular docking, which aims to understand, at the molecular level, some of the biological effects ascribed to infusions from this plant.
\end{abstract}

Keywords: Centaurium erythraea; acetylcholinesterase; HMG-CoA reductase; gentiopicroside; xanthones; docking studies

\section{Introduction}

Centaurium erythraea (C. erythraea) is a plant belonging to the Gentianaceae family, known as common centaury, growing in almost all Europe, North Africa and Southwest Asia [1]. It is a medicinal plant with several applications, among which gastrointestinal motility [1], gastric damage [2] as well as reduction of total blood cholesterol [3] can be mentioned. The European Medicine Agency (EMA) has a report on its applications [4] and in China a secoiridoid present in this plant was approved as a new drug to treat acute jaundice and chronic active hepatitis [5]. 
The gastro-protective effect observed with C. erythraea aqueous-ethanol extracts could, in part, be explained by its antioxidant activity [2,6]. Radical species can be formed inside cells due to several oxidation processes. These reactive oxygen and nitrogen species induce modifications in DNA, protein, and lipid molecules, which can lead to severe cell damage [7]. Cells have several repairing mechanisms to deal with these damaged molecules and many antioxidant compounds that avoid radical formation or promptly neutralize their effect $[8,9]$. Several diseases are related to oxidative processes in cells $[10,11]$.

Aerial parts of C. erythraea have shown antimicrobial [12], gastro-protective [2] properties, and gentiopicroside from C.erythraea has shown anti-inflammatory effects [13], without exhibiting toxicity towards laboratory animals (rodents) [14]. Extracts from this plant are rich in secoiridoid glycosides, namely gentiopicroside, sweroside, swertiamarin, and in xanthone derivatives $[15,16]$. Several biological activities have been attributed to gentiopicroside, namely inhibition of the spontaneous contraction of the ileum smooth muscle [17], including analgesic, anti-inflammatory and anti-acetylcholinesterase activities $[18,19]$. This iridoid glycoside offers hepatoprotection against compounds that produce liver failure [20] and can also protect DNA from damage [21]. Gentiopicroside was able to increase gastrointestinal motility by modifying the expression of several hormones related with intestinal propelling [22] as well as reducing the total cholesterol level in laboratory animals [23]. Xantones, which are also present in C. erythraea, have shown several biological effects, including antitumor and anti-inflammatory activities [24,25]. Xanthone derivatives can inhibit acetylcholinesterase (AChE) and block the acetylcholinesterase-induced $\beta$-amyloid aggregation [26]. These compounds are also known for their antiproliferative effect and their ability to inhibit several molecular targets in the tumor cells, including kinases, cyclooxygenases and DNA polymerases [8].

The plant extracts effects mentioned, like gastro-intestinal propelling and blood cholesterol reduction, in addition to its association with Alzheimer's Disease, have guided us to evaluate the activities of AChE and 3-hydroxy-3-methyl-glutaryl-coenzyme A reductase (HMGR). AChE (EC 3.1.1.7) is an enzyme located in the synaptic clefts and neuromuscular junctions [26] that catalyzes the hydrolysis of the neurotransmitter acetylcholine, which is essential for neuronal connectivity and junction contraction mechanism [27]. AChE has also been shown to influence gastrointestinal and colon motility [28] and its reversible inhibition can help treat gastrointestinal (GI) disorders [19-31] and Alzheimer's disease [32]. HMGR (EC 1.1.1.34) enzyme is an important regulator of the cholesterol biosynthesis pathway [33] and its inhibition by statins has been used therapeutically to reduce total blood cholesterol levels [34].

The aim of this study is to identify the key compounds present in C. erythraea decoction, a common way of consuming herbal beverages, and to test for its antioxidant effects, and for AChE and HMGR inhibitory activities, which can help explain the decoctions impact in ethno-medicine [1]. In this top-down approach, we will also perform computational molecular docking calculations to help rationalize the molecular details of the mechanisms of action and pinpoint the individual contributions of each compounds. In overall, this study contributes to the scientific knowledge on the mechanisms of action of C. erythraea decoctions, an herb described by the Committee on Herbal Medicinal Products (HMPC, from EMA).

\section{Results and Discussion}

\subsection{Decoction Phenolic Compounds}

Decoctions of C. erythraea were prepared and analyzed by reversed-phase high-performance liquid chromatography with diode array detector (RP-HPLC-DAD), Figure 1. Since water can extract sugar polymers, ethanol precipitation of these compounds (mucilages' precipitation) was carried out and the supernatant decoction mucilage free $\left(\mathrm{DM}_{\mathrm{f}}\right)$ was analyzed by RP-HPLC-DAD, Figure 1 . The amount of precipitated material was very small (only 5.5\%), meaning that C. erythraea has a very low amount of sugar polymers. The pellet did not have phenolic compounds since no peaks were 
seen in the chromatogram, Figure 1. In this chromatogram one major peak is detected around $11 \mathrm{~min}$ and several compounds appear after this retention time. It can be seen that the decoction without mucilages overlap with the complete extract and the pellet has no detectable compounds.

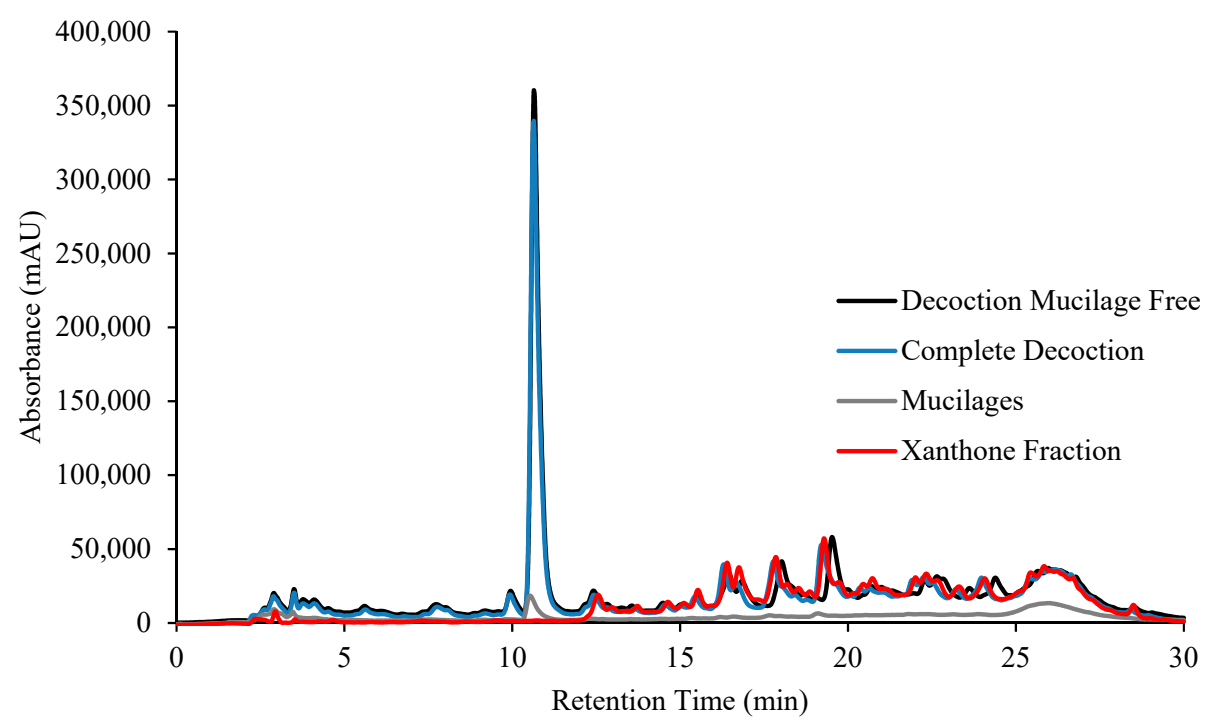

Figure 1. Reversed-phase high-performance liquid chromatography with diode array detector (RP-HPLC-DAD) chromatogram of decoction of C. erythraea and its isolated fractions.

In order to identify the compounds LC-MS/MS was carried out. LC-MS in the negative and positive mode (Figure 2a,b, respectively) and LC-MS/MS allowed the identification of the compounds indicated in Table 1, either by using information from the literature or by taking into account the exact mass. The first chromatogram in Figure $2 a, b$, is the BPC chromatogram with all the compounds present in the complete extract. This chromatogram is identical to that obtained by RP-HPLC-DAD, that is a major compound followed by lots of several compounds with lower intensity. The identification of the compounds indicated the presence of five secoiridoids, six xanthones and one flavonoid (quercetin). The major compound is gentiopicroside, a secoiridoid structure compound characteristic of the Gentianaceae family to which C. erythraea belongs [35]. The compounds with retention time between 8 and 30 min were identified as xanthones derivatives and quercetin, Table 1 . Before this retention time most of the compounds had the same structure type of secoiridoids. Due to the similarity between the chromatograms and to the use of the standard compound gentiopicroside, the peak with the highest intensity in RP-HPLC-DAD (Figure 1) contains the secoiridoid derivatives. The small peaks at higher retention time belong to xanthone type compounds, according to the mass identification results.

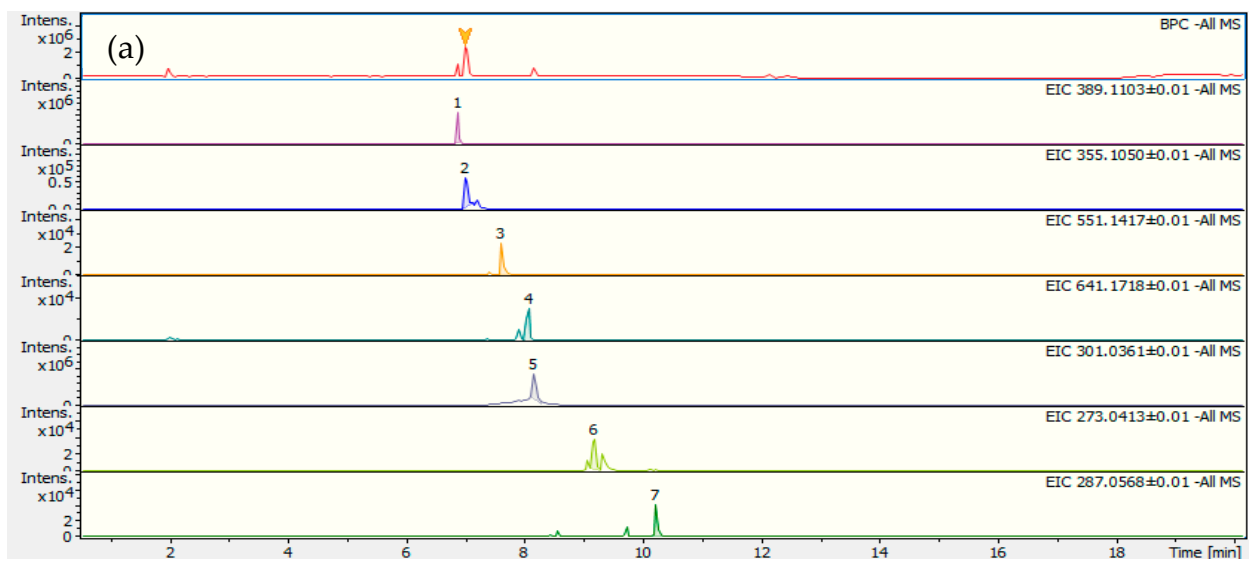

Figure 2. Cont. 


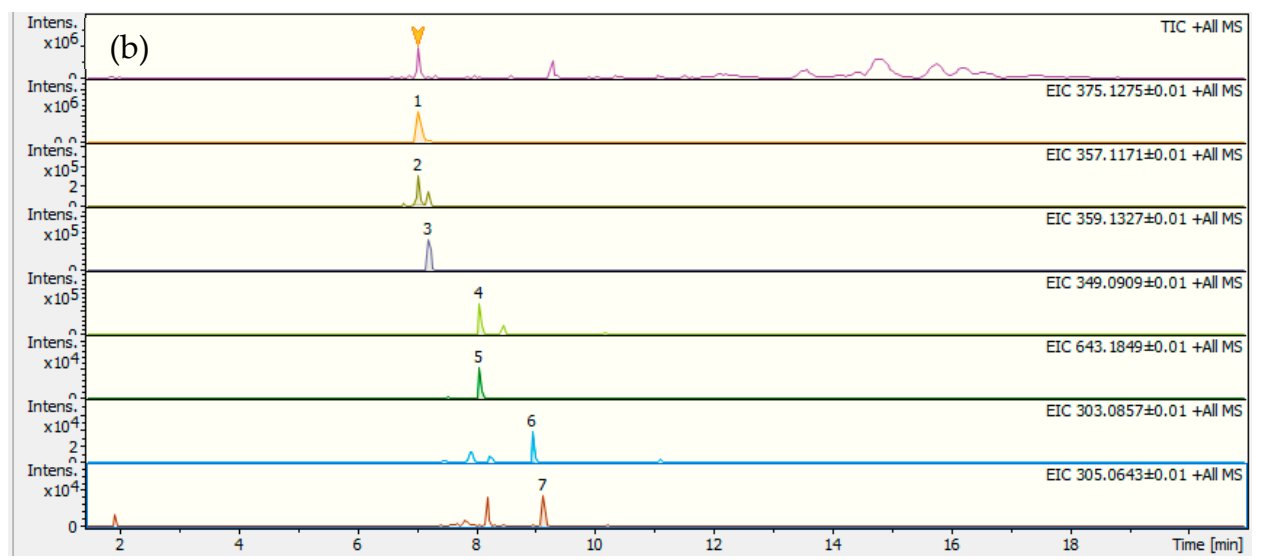

Figure 2. Total ionic chromatogram and ionic chromatograms extracted from ions identified in C. erythraea complete decoction: (a) liquid chromatography-electrospray ionization tandem mass spectrometry (LC-ESI (-) MS/MS) and (b) LC-ESI (+) MS/MS. Peaks 1-7 are identified in Table 1.

Table 1. Identification proposal of the compounds present in the complete decoction by LC-MS/MS in ESI negative and positive mode. Peaks with a minus/plus superscript were analyzed in negative/positive mode. Compounds are indicated by retention time ( $\mathrm{Rt}$ ) order and numbered according to the appearance in each chromatogram, negative $[\mathrm{M}-\mathrm{H}]^{-}$or positive mode $[\mathrm{M}+\mathrm{H}]^{+}$.

\begin{tabular}{|c|c|c|c|c|c|c|}
\hline Peak & $\begin{array}{c}\mathrm{Rt} \\
(\mathrm{min})\end{array}$ & $\begin{array}{l}{[\mathrm{M}-\mathrm{H}]^{-} /} \\
{[\mathrm{M}+\mathrm{H}]^{+}}\end{array}$ & Formula & $\begin{array}{c}\text { Error } \\
(\Delta \text { ppm })\end{array}$ & $\begin{array}{c}\text { Main MS }{ }^{2} \text { Fragment ions } \\
{[\mathrm{m} / \mathrm{z}, \text { Attribution, (Intensity \%)] }}\end{array}$ & Proposed Compound \\
\hline $1^{-}$ & 6.9 & 389.1102 & $\mathrm{C}_{16} \mathrm{H}_{22} \mathrm{O}_{11}$ & -3.1 & 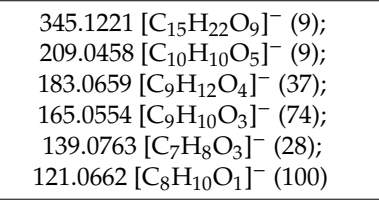 & Secologanoside \\
\hline $3^{-}$ & 7.7 & 551.1417 & $\mathrm{C}_{25} \mathrm{H}_{28} \mathrm{O}_{14}$ & -2.0 & $\begin{array}{c}\text { 507.1517 }\left[\mathrm{C}_{24} \mathrm{H}_{28} \mathrm{O}_{12}\right]^{-}(66) ; \\
393.1187\left[\mathrm{C}_{19} \mathrm{H}_{22} \mathrm{O}_{9}\right]^{-}(80) ; \\
389.1081\left[\mathrm{C}_{16} \mathrm{H}_{22} \mathrm{O}_{11}\right]^{-}(51) ; \\
345.1195\left[\mathrm{C}_{15} \mathrm{H}_{22} \mathrm{O}_{9}\right]^{-}(44) ; \\
323.0793\left[\mathrm{C}_{15} \mathrm{H}_{16} \mathrm{O}_{8}\right]^{-}(51) ; \\
301.0352\left[\mathrm{C}_{14} \mathrm{H}_{22} \mathrm{O}_{7}\right]^{-}(40) ; \\
281.0676\left[\mathrm{C}_{13} \mathrm{H}_{14} \mathrm{O}_{7}\right]^{-}(68) ; \\
161.0236\left[\mathrm{C}_{9} \mathrm{H}_{6} \mathrm{O}_{3}\right]^{-}(100)\end{array}$ & Caffeoyl-6'-secologa-noside \\
\hline $4^{-}$ & 8.1 & 641.1738 & $\mathrm{C}_{28} \mathrm{H}_{34} \mathrm{O}_{17}$ & -2.3 & $\begin{array}{c}347.0776\left[\mathrm{C}_{17} \mathrm{H}_{16} \mathrm{O}_{8}\right]^{-}(59) ; \\
332.0543\left[\mathrm{C}_{16} \mathrm{H}_{13} \mathrm{O}_{8}\right]^{-}(100) ; \\
301.0367\left[\mathrm{C}_{15} \mathrm{H}_{11} \mathrm{O}_{7}\right]^{-}(23)\end{array}$ & $\begin{array}{l}\text { Di-hydroxy-tetrame-toxy } \\
\text {-O-pentosyl-hexosylxanthone }\end{array}$ \\
\hline $5^{-}$ & 8.2 & 301.0362 & $\mathrm{C}_{15} \mathrm{H}_{10} \mathrm{O}_{7}$ & -2.7 & - & Quercetin \\
\hline $6^{-}$ & 9.2 & 273.0413 & $\mathrm{C}_{14} \mathrm{H}_{10} \mathrm{O}_{6}$ & -3.1 & $\begin{array}{l}258.0177\left[\mathrm{C}_{13} \mathrm{H}_{7} \mathrm{O}_{6}\right]^{-}(100) ; \\
257.0102\left[\mathrm{C}_{13} \mathrm{H}_{6} \mathrm{O}_{6}\right]^{-}(20) ; \\
230.0222\left[\mathrm{C}_{12} \mathrm{H}_{7} \mathrm{O}_{5}\right]^{-}(10) ; \\
229.0144\left[\mathrm{C}_{12} \mathrm{H}_{6} \mathrm{O}_{5}\right]^{-}(17)\end{array}$ & Tri-hydroxy-monome-toxyxanthone \\
\hline $7^{-}$ & 10.3 & 287.0568 & $\mathrm{C}_{15} \mathrm{H}_{12} \mathrm{O}_{6}$ & -2.5 & $\begin{array}{l}272.0335\left[\mathrm{C}_{14} \mathrm{H}_{9} \mathrm{O}_{6}\right]^{-}(22) ; \\
257.0096\left[\mathrm{C}_{13} \mathrm{H}_{6} \mathrm{O}_{6}\right]^{-}(100) ; \\
229.0143\left[\mathrm{C}_{12} \mathrm{H}_{6} \mathrm{O}_{5}\right]^{-}(22)\end{array}$ & Di-hydroxy-dimetho-xyxanthone \\
\hline $1^{+}$ & 7.1 & 375.1275 & $\mathrm{C}_{16} \mathrm{H}_{22} \mathrm{O}_{10}$ & 2.9 & $\begin{array}{c}\text { 195.0645 }\left[\mathrm{C}_{10} \mathrm{H}_{10} \mathrm{O}_{4}\right]^{+}(9) ; \\
\text { 177.0539 }\left[\mathrm{C}_{10} \mathrm{H}_{8} \mathrm{O}_{3}\right]^{+}(100) ; \\
\text { 167.0696 }\left[\mathrm{C}_{9} \mathrm{H}_{10} \mathrm{O}_{3}\right]^{+}(17)\end{array}$ & Swertiamarin \\
\hline $2^{+}$ & 7.1 & 357.1171 & $\mathrm{C}_{16} \mathrm{H}_{20} \mathrm{O}_{9}$ & 2.6 & $\begin{array}{c}\text { 177.0538 }\left[\mathrm{C}_{10} \mathrm{H}_{8} \mathrm{O}_{3}\right]^{+}(100) \\
\text { 163.0378 }\left[\mathrm{CC}_{9} \mathrm{H}_{6} \mathrm{O}_{3}\right]^{+}(70) ; \\
149.0601\left[\mathrm{C}_{9} \mathrm{H}_{8} \mathrm{O}_{2}\right]^{+}(45)\end{array}$ & Gentiopicroside \\
\hline $3^{+}$ & 7.2 & 359.1327 & $\mathrm{C}_{16} \mathrm{H}_{22} \mathrm{O}_{9}$ & 2.8 & $\begin{array}{c}\text { 197.0798 }\left[\mathrm{C}_{10} \mathrm{H}_{12} \mathrm{O}_{4}\right]^{+}(100) ; \\
\text { 179.0693 }\left[\mathrm{C}_{10} \mathrm{H}_{10} \mathrm{O}_{3}\right]^{+}(50) ; \\
\text { 177.0536 }\left[\mathrm{C}_{10} \mathrm{H}_{8} \mathrm{O}_{3}\right]^{+}(63) ; \\
\text { 149.0597 }\left[\mathrm{C}_{9} \mathrm{H}_{8} \mathrm{O}_{2}\right]^{+}(41) ; \\
\text { 127.0420 }\left[\mathrm{C}_{6} \mathrm{H}_{6} \mathrm{O}_{3}\right]^{+}(84)\end{array}$ & Sweroside \\
\hline
\end{tabular}


Table 1. Cont.

\begin{tabular}{|c|c|c|c|c|c|c|}
\hline Peak & $\begin{array}{c}\mathrm{Rt} \\
(\mathrm{min})\end{array}$ & $\begin{array}{l}{[\mathbf{M}-\mathbf{H}]^{-} /} \\
{[\mathbf{M}+\mathbf{H}]^{+}}\end{array}$ & Formula & $\begin{array}{c}\text { Error } \\
(\Delta \text { ppm })\end{array}$ & $\begin{array}{c}\text { Main } \text { MS }^{2} \text { Fragment ions } \\
{[m / z, \text { Attribution, (Intensity \%)] }}\end{array}$ & Proposed Compound \\
\hline $4^{+}$ & 8.1 & 349.0909 & $\mathrm{C}_{17} \mathrm{H}_{16} \mathrm{O}_{8}$ & 2.6 & $\begin{array}{c}\text { 334.0678 }\left[\mathrm{C}_{16} \mathrm{H}_{13} \mathrm{O}_{8}\right]^{+}(7) ; \\
319.0443\left[\mathrm{C}_{15} \mathrm{H}_{10} \mathrm{O}_{8}\right]^{+}(100) ; \\
301.0338\left[\mathrm{C}_{15} \mathrm{H}_{8} \mathrm{O}_{7}\right]^{+}(12) ; \\
291.0496\left[\mathrm{C}_{14} \mathrm{H}_{10} \mathrm{O}_{7}\right]^{+}(9)\end{array}$ & Di-hydroxy-tetrame-thoxyxanthone \\
\hline $6^{+}$ & 9.0 & 303.0857 & $\mathrm{C}_{16} \mathrm{H}_{14} \mathrm{O}_{6}$ & 1.9 & $\begin{array}{c}\text { 288.0621 }\left[\mathrm{C}_{15} \mathrm{H}_{11} \mathrm{O}_{6}\right]^{+}(100) \\
\text { 273.0389 }\left[\mathrm{C}_{14} \mathrm{H}_{8} \mathrm{O}_{6}\right]^{+}(19) ; \\
\text { 245.0438 }\left[\mathrm{C}_{13} \mathrm{H}_{8} \mathrm{O}_{5}\right]^{+}(37)\end{array}$ & Monohydroxy-trime-toxyxanthone \\
\hline $7^{+}$ & 9.1 & 305.0643 & $\mathrm{C}_{15} \mathrm{H}_{12} \mathrm{O}_{7}$ & 4.2 & $\begin{array}{c}290.0416\left[\mathrm{C}_{14} \mathrm{H}_{9} \mathrm{O}_{7}\right]^{+}(86) \\
275.0180\left[\mathrm{C}_{13} \mathrm{H}_{6} \mathrm{O}_{7}\right]^{+}(100) \\
247.0238\left[\mathrm{C}_{12} \mathrm{H}_{6} \mathrm{O}_{6}\right]^{+}(30)\end{array}$ & Tri-hydroxy-dimeto-xyxanthone \\
\hline
\end{tabular}

The separation between xantones and iridoids was relatively easy due to their structural differences. A fraction containing mainly xanthones $(\mathrm{XF})$ was obtained by repeatedly injecting the $\mathrm{DM}_{\mathrm{f}}$ in the HPLC-DAD and collecting only the compounds coming out the column between 11.5 and $30 \mathrm{~min}$. This fraction was injected again in the chromatographic system to confirm that the compounds belonged to the xanthone fraction in Figure 1.

Since several biological activities have been attributed to either gentiopicroside or xanthone derivatives, we have complemented the analysis of the $C$. erythraea complete decoctions with studies of $\mathrm{DM}_{\mathrm{f}}$ and XF.

\subsection{Total Phenols Quantfication}

Total phenols were quantified in all samples, Table 2, and the amounts detected by the Folin-Ciocalteu method were quite low. This was expected since this method quantifies the phenol hydroxyl groups, which are absent in some of the identified compounds from the HPLC-DAD and LC-MS/MS results, such as gentiopicroside, swertiamarin or sweroside. The aqueous extract (D) has the highest amount of phenolic compounds mesasured as Gallic Acid Equivalents (GAE) (22.37 $\pm 0.36 \mu \mathrm{g} \mathrm{GAE} / \mathrm{mg}$ extract), followed by $\mathrm{DM}_{\mathrm{f}}(18.82 \pm 0.25 \mu \mathrm{g}$ GAE$/ \mathrm{mg}$ extract $)$ and finally XF $(16.31 \pm 0.25 \mu \mathrm{g} \mathrm{GAE} / \mathrm{mg}$ extract $)$. These values were statistically different at $p \leq 0.05$.

Table 2. Total phenols and bioactivities of the complete decoction (D) of C. erythraea, the decoction mucilage free $\left(\mathrm{DM}_{\mathrm{f}}\right)$, the xanthones fraction $(\mathrm{XF})$ and the standard gentiopicroside.

\begin{tabular}{|c|c|c|c|c|c|c|}
\hline \multirow[b]{2}{*}{ Extracts/Standard } & \multirow{2}{*}{$\begin{array}{l}\text { Total Phenols } \\
\text { ( } \mu \text { g GAE/mg of } \\
\text { Extract) }\end{array}$} & \multicolumn{3}{|c|}{ Antioxidant Activity } & \multicolumn{2}{|c|}{ Enzyme Inhibitory Activity } \\
\hline & & $\begin{array}{c}\text { DPPH } \\
(50 \mu \mathrm{g} / \mathrm{mL})(\%)\end{array}$ & $\begin{array}{c}\text { TBARS } \\
(400 \mu \mathrm{g} / \mathrm{mL})(\%)\end{array}$ & $\begin{array}{c}\mathrm{EC}_{50} \mathrm{NO}^{\prime} \mathrm{s} \\
(\mu \mathrm{g} / \mathrm{mL})\end{array}$ & $\begin{array}{c}\text { AChE } \\
(500 \mu \mathrm{g} / \mathrm{mL})(\%)\end{array}$ & $\begin{array}{c}\text { HMGR } \\
(10 \mu \mathrm{g} / \mathrm{mL})(\%)\end{array}$ \\
\hline $\mathrm{D}$ & $22.37 \pm 0.36$ & $25.25 \pm 0.72$ & $32.23 \pm 0.93$ & $774.9 \pm 13.8$ & $56.43 \pm 0.84$ & $47.99 \pm 0.47$ \\
\hline $\mathrm{DM}_{\mathrm{f}}$ & $18.82 \pm 0.25$ & $21.95 \pm 0.46$ & - & - & $47.09 \pm 0.95$ & - \\
\hline XF & $16.31 \pm 0.25$ & $17.63 \pm 0.41$ & - & - & $59.81 \pm 0.7$ & $26.86 \pm 0.87$ \\
\hline Gentio-picroside & - & $1.31 \pm 0.53$ & - & - & $6.51 \pm 0.18$ & $57.95 \pm 0.51$ \\
\hline
\end{tabular}

\subsection{Antioxidant Activity}

In recent years, there has been a great deal of attention towards natural antioxidants that can be used in our diet and help the organism counteract the oxidative stress. To evaluate the biological activities of the compounds present in the decoctions, we used both XF and the standard gentiopicroside to represent the most abundant compound of the chromatogram. The most widely used method to measure antioxidant activities is the 2,2-diphenyl-1-picrylhydrazyl (DPPH) scavenging radical test [36], but due to some reported drawbacks of this method [37] and to the complexity of antioxidant mechanisms inside cells, we complemented our study with other fast and inexpensive in vitro methodologies, which model the in vivo antioxidant processes. In these assays, the antioxidant potential of C. erythraea was evaluated by its ability to reduce the DPPH radical, to inhibit lipid peroxidation and to capture nitric oxide radicals avoiding its reaction with biological molecules. 


\subsubsection{DPPH (2,2-Diphenyl-1-Picrylhydrazyl) Radical Scavenging Activity}

As shown in Table 2, using the same concentration $(50 \mu \mathrm{g} / \mathrm{mL}) \mathrm{D}$ is the one with the highest percentage of free radical capture (approximately $25 \%$ ) while the $\mathrm{DM}_{\mathrm{f}}$ has a radical reduction percentage of $\sim 22 \%$. These results suggest that during the mucilage precipitation process some antioxidant compounds are retained in the mucilages or that some constitutive compounds of mucilages have the ability to reduce the DPPH radical. XF has a good antioxidant activity compared to the complete decoction; $68 \%$ of the DPPH scavenging capacity in the complete decoction corresponds to the xanthone fraction or $75 \%$ relative to the $\mathrm{DM}_{\mathrm{f}}$. This suggests a low antioxidant activity of secoiridoids detected in this decoction. As expected, the antioxidant activities measured correlate well with the amount of total phenols quantified in the different samples $\left(r^{2}=0.9677\right)$. Based on the results obtained by LC-MS/MS, we propose that most xanthones have hydroxyl groups in their structure that can easily provide electrons and quench the DPPH radical.

The gentiopicroside standard showed a low antioxidant activity $(\sim 1 \%)$, while for commercial butylated hydroxytoluene (BHT), rutin and quercetin the $\mathrm{EC}_{50}$ values are $9.89 \mu \mathrm{g} / \mathrm{mL}, 6.27 \mu \mathrm{g} / \mathrm{mL}$, and $3.23 \mu \mathrm{g} / \mathrm{mL}$, respectively. The gentiopicroside result was expected since this compound has no radical stabilizing group, hence it is unable to donate electrons to the radical form of DDPH.

It is noteworthy that studies carried out with C. erythraea secoiridoides revealed that neither swertiamarin nor sweroside, identified by LC-MS/MS in this work, have antioxidant activity [12]. Therefore, these data combined with the practically non-existent activity of gentiopicroside may explain the low antioxidant activity of this extract when compared to the commercial standards mentioned above. Furthermore, our antioxidant activity results are in good agreement with other plant extract having similar compounds [38,39].

\subsubsection{Lipoperoxidation Inhibition}

The antioxidant activity measured as TBARs formation indicates a capacity to counteract lipid oxidation. As presented in Table 2, for the final concentration of $400 \mu \mathrm{g} / \mathrm{mL}$ D has an inhibition of approximately $32 \%$, which is lower than that of BHT, the commercial standard $(49.09 \mu \mathrm{g} / \mathrm{mL})$. This activity is lower than the one obtained with plant-water extracts containing polyphenols [40]. In C. erythraea extracts, secoiridoids and xanthones are the main components and although xanthones with free hydroxyl groups have the capacity to avoid lipid peroxidation [41], most of those detected in our study have several hydroxyl groups methylated or functionalized with sugar moieties. These modifications reduce significantly the number of free hydroxyl groups available, which are indeed the source for the antioxidant activity detected in the present work.

\subsubsection{Nitric Oxide Radical Scavenging}

$\mathrm{NO}^{\bullet}$ is a free radical species naturally generated in the cell with important physiological functions. However, it becomes a hazardous compound when it reacts with superoxide radical, forming the peroxynitrite anion $\left(\mathrm{ONOO}^{-}\right)$, a powerful oxidant [42]. The $\mathrm{NO}^{\bullet}$ radical scavenging activity is a measure of peroxynitrite elimination, hence, of avoiding oxidative stress in the cell. In this method $\mathrm{NO}{ }^{\bullet}$ is formed from sodium nitroprusside and it reacts with molecular oxygen to produce nitrate and nitrite, the latter being quantified using Griess reagent [43]. Using this method to model NO• synthesis in the cell, we can measure the radical scavenging ability of the decoction, Table 2 . In this study the aqueous extract $(D)$ has a lower inhibitory capacity $\left(\mathrm{EC}_{50}=775 \mu \mathrm{g} / \mathrm{mL}\right)$ than rutin $\left(\mathrm{EC}_{50}=314 \mu \mathrm{g} / \mathrm{mL}\right)$, a potent antioxidant known for its $\mathrm{NO}^{\bullet}$ scavenging ability. Nevertheless, decoctions containing a mixture of flavonoid derivatives [43] have shown a higher activity, suggesting that neither secoiridoids nor xanthones have a significant capacity for capturing the NO radical. 


\subsection{Enzyme Inhibition}

\subsubsection{Acetylcholinesterase (AChE) Inhibitory Activities and Docking Studies}

C. erythraea is used as decoctions or infusions to improve the food digestive process [22]. One way of improving this digestive process is increasing the intestinal transit, which can be accomplished by inhibiting the enzyme acetylcholinesterase (AChE) in the neuromuscular junctions. This mechanism has been shown to accelerate the gastrointestinal motility in post-operated human patients and animals [28,30]. The AChE inhibition assays were performed using $\mathrm{D}, \mathrm{DM}_{\mathrm{f}}, \mathrm{XF}$ and gentiopicroside standard. No correlation was observed between the amount of total phenols present in the fractions and the enzyme inhibitory activity $\left(\mathrm{r}^{2}=0.0256\right)$, which was expected since there are many factors that influence the inhibition constant of AChE and most of them are not related with the number of phenol groups in the compound. Furthermore, not all compounds are able to fit inside the enzyme active site in the most effective way.

For the final concentration of $500 \mu \mathrm{g} / \mathrm{mL}$, the sample that showed a higher inhibitory activity was XF $(\sim 60 \%)$, followed by D ( 56\%) and by the $\mathrm{DM}_{\mathrm{f}}(\sim 47 \%)$. Previous studies with 1,5,8-trihydroxy3-methoxyxanthone (isolated from Gentiana campestris, also belonging to the Gentianaceae family) showed enzyme inhibition values very similar to the commercial standard galantamine [44], highlighting the role these compounds can play in the treatment of digestive problems and even Alzheimer's Disease. Due to the low activity of D containing the major component gentiopicroside relatively to the $\mathrm{XF}$, the standard compound was also added in this study and its AChE inhibitory activity determined, Table 2 . The AChE inhibition using the pure compound, at $500 \mu \mathrm{L} / \mathrm{mL}$, was very low $(6.5 \%)$, confirming its poor contribution compared with the standard galantamine $(0.14 \mu \mathrm{g} / \mathrm{mL}) \mathrm{or}$ donepezil (2 ng/mL) [45].

The clear differences in inhibition capacities of AChE by gentiopicroside and xanthone led us to investigate the compound/enzyme interactions at the molecular level. We performed computational docking calculations of the poor inhibitor gentiopicroside and several xanthone derivatives (Figure 3) that comply with the molecular weight reported by the LC-MS/MS assay (Table 1). We divided the tested xanthones into three classes: xanthones previously described in the literature (Table 3 xan01-11), rationally designed xanthone compounds (Table 3 xan12-15) and xanthone derivatives from the most potent inhibitors of the two previous groups (Table 3 xan08.1-15.1). Xanthones identified in the present work are indicated in Table 3 by the corresponding peak number in Table 1. In this study several hypotheses were proposed for the localization of $\mathrm{OH}$ and OMe groups according to different identifications reported in the literature. This fact attributes several compounds for the same peak identified by LC-MS/MS.<smiles>C=C[C@H]1C2=CCOC(=O)C2=CO[C@@H]1O[C@H]1O[C@H](CO)[C@@H](O)[C@H](O)[C@H]1O</smiles>

(a)<smiles></smiles>

(b)

Figure 3. Schematic structures: (a) gentiopicroside; (b) xanthone (template). The different substitutions in the R1-R8 positions, leading to the xanthone molecules used in the docking protocol, are described in Table 3. 
Table 3. Summary of all xanthones used in the AChE molecular docking calculations with their binding energies and inhibition constants. The R1-R8 positions relate to the xanthone template (Figure 3) and the $\mathrm{OH} / \mathrm{OMe}$ labels refer to the hydroxyl and methoxy groups. The peaks refer to the positive and negative ESI modes in Table 1.

\begin{tabular}{|c|c|c|c|c|c|c|c|c|c|c|c|}
\hline Final Name & Peak & $\mathbf{R}_{\mathbf{1}}$ & $\mathbf{R}_{2}$ & $\mathbf{R}_{3}$ & $\mathbf{R}_{4}$ & $\mathbf{R}_{5}$ & $\mathbf{R}_{6}$ & $\mathbf{R}_{7}$ & $\mathbf{R}_{8}$ & $\begin{array}{c}\Delta \mathrm{G}_{\text {BIND }} \\
\text { (kcal/mol) }\end{array}$ & $\begin{array}{c}\mathrm{K}_{\mathbf{i}} \\
(\mu \mathrm{M})\end{array}$ \\
\hline xan01* & $4^{+}$ & $\mathrm{OH}$ & & $\mathrm{OMe}$ & & $\mathrm{OMe}$ & $\mathrm{OMe}$ & $\mathrm{OMe}$ & $\mathrm{OH}$ & -6.0 & 36.9 \\
\hline xan02* & $4^{+}$ & $\mathrm{OH}$ & & $\mathrm{OMe}$ & & $\mathrm{OMe}$ & $\mathrm{OH}$ & $\mathrm{OMe}$ & $\mathrm{OMe}$ & -5.6 & 77.6 \\
\hline $\operatorname{xan} 03 *$ & $6^{+}$ & $\mathrm{OH}$ & $\mathrm{OMe}$ & $\mathrm{OMe}$ & & $\mathrm{OMe}$ & & & & -6.9 & 8.9 \\
\hline xan04* & $6^{+}$ & $\mathrm{OMe}$ & & $\mathrm{OH}$ & & $\mathrm{OMe}$ & $\mathrm{OMe}$ & & & -6.6 & 15.3 \\
\hline xan05* (decussatin) & $6^{+}$ & $\mathrm{OH}$ & & $\mathrm{OMe}$ & & & & $\mathrm{OMe}$ & $\mathrm{OMe}$ & -5.7 & 65.6 \\
\hline xan $06^{*}$ & $6^{+}$ & $\mathrm{OH}$ & & $\mathrm{OMe}$ & & $\mathrm{OMe}$ & $\mathrm{OMe}$ & & & -5.9 & 50.9 \\
\hline xan $07 *$ & $7^{+}$ & $\mathrm{OH}$ & $\mathrm{OMe}$ & $\mathrm{OH}$ & & $\mathrm{OMe}$ & $\mathrm{OH}$ & & & -6.1 & 35.1 \\
\hline xan08* & $6^{-}$ & $\mathrm{OH}$ & & $\mathrm{OMe}$ & & $\mathrm{OH}$ & $\mathrm{OH}$ & & & -7.5 & 2.9 \\
\hline xan09* (bellidifolin) & $6^{-}$ & $\mathrm{OH}$ & & $\mathrm{OMe}$ & & $\mathrm{OH}$ & & & $\mathrm{OH}$ & -7.5 & 2.9 \\
\hline $\operatorname{xan} 10 *$ & $6^{-}$ & $\mathrm{OH}$ & $\mathrm{OMe}$ & $\mathrm{OH}$ & & $\mathrm{OH}$ & & & & -6.5 & 17.0 \\
\hline $\operatorname{xan} 11 *$ & $7^{-}$ & $\mathrm{OH}$ & & $\mathrm{OMe}$ & & $\mathrm{OMe}$ & $\mathrm{OH}$ & & & -7.1 & 5.9 \\
\hline xan12 & $4^{+}$ & $\mathrm{OH}$ & $\mathrm{OMe}$ & & $\mathrm{OMe}$ & $\mathrm{OMe}$ & & $\mathrm{OMe}$ & $\mathrm{OH}$ & -7.5 & 3.4 \\
\hline xan13 & $7^{+}$ & & $\mathrm{OH}$ & & $\mathrm{OH}$ & $\mathrm{OH}$ & & $\mathrm{OMe}$ & $\mathrm{OMe}$ & -6.4 & 19.8 \\
\hline xan14 & $6^{-}$ & $\mathrm{OH}$ & & & & $\mathrm{OH}$ & $\mathrm{OMe}$ & $\mathrm{OH}$ & & -5.9 & 50.0 \\
\hline xan15 & $6^{-}$ & $\mathrm{OH}$ & & & $\mathrm{OH}$ & $\mathrm{OH}$ & & $\mathrm{OMe}$ & & -7.5 & 3.0 \\
\hline xan08.1 & & $\mathrm{OH}$ & & $\mathrm{OH}$ & & $\mathrm{OH}$ & $\mathrm{OH}$ & & & -7.3 & 4.2 \\
\hline xan08.2 & & $\mathrm{OH}$ & & & & $\mathrm{OH}$ & $\mathrm{OH}$ & & & -7.4 & 3.9 \\
\hline xan08.3 & & $\mathrm{OH}$ & & $\mathrm{OMe}$ & $\mathrm{OH}$ & $\mathrm{OH}$ & $\mathrm{OH}$ & & & -7.1 & 6.0 \\
\hline xan09.1 & & $\mathrm{OH}$ & & $\mathrm{OH}$ & & $\mathrm{OH}$ & & & $\mathrm{OH}$ & -7.4 & 3.5 \\
\hline xan09.2 & & $\mathrm{OH}$ & & & & $\mathrm{OH}$ & & & $\mathrm{OH}$ & -6.8 & 10.1 \\
\hline xan12.1 & & $\mathrm{OH}$ & & & $\mathrm{OMe}$ & $\mathrm{OMe}$ & & $\mathrm{OMe}$ & $\mathrm{OH}$ & -7.9 & 1.6 \\
\hline xan12.2 & & $\mathrm{OH}$ & $\mathrm{OH}$ & & $\mathrm{OMe}$ & $\mathrm{OMe}$ & & $\mathrm{OMe}$ & $\mathrm{OH}$ & -7.2 & 5.2 \\
\hline xan12.3 & & $\mathrm{OH}$ & $\mathrm{OMe}$ & & $\mathrm{OH}$ & $\mathrm{OMe}$ & & $\mathrm{OMe}$ & $\mathrm{OH}$ & -7.4 & 4.0 \\
\hline xan12.4 & & $\mathrm{OH}$ & $\mathrm{OMe}$ & & $\mathrm{OMe}$ & $\mathrm{OMe}$ & & $\mathrm{OH}$ & $\mathrm{OH}$ & -7.3 & 4.4 \\
\hline xan15.1 & $7^{-}$ & $\mathrm{OMe}$ & & & $\mathrm{OH}$ & $\mathrm{OH}$ & & $\mathrm{OMe}$ & & -6.7 & 12.3 \\
\hline
\end{tabular}

* The position of substituent groups on the xanthone structure (Figure 2) indicated in this table was indicated in the literature: [15] for xan01, 02, 03, 04, 07, 08, 09, 10 and 11; [46] for xan01, 04, 05, 06 and 10; [47] for xan11.

The docking calculations that were performed show that these two compound families bind to distinct pocket regions. Gentiopicroside binds in a deeper position, near the catalytic triad of AChE, while xanthones bind at the access tunnel gorge (Figure 4A,B). The two binding positions are complementary and together resemble donepezil binding mode. Like galantamine, donepezil is a very potent $\mathrm{AChE}$ inhibitor and we expected that neither gentiopicroside nor any xanthone can be as strong inhibitors, because these only exhibit a fraction of the shape-complementarity and the interactions donepezil establishes in the pocket of AChE. According to our simulations, gentiopicroside is a modest AChE inhibitor (calculated $K_{i}=62.3 \mu \mathrm{M}$ ) as a consequence of not interacting strongly with the enzyme. We observe only a few individual hydrogen bonds between the glycoside group and the tyrosine side chains, while the rest of the gentiopicroside molecule binds near the catalytic triad without establishing noticeable direct interactions (Figure 4C).

The preferred binding mode of most xanthones is at the access tunnel of the active site where the compounds seem to maximize the number of interactions and present a strong shape complementarity. The low polarity of this class of molecules leads to an increased binding affinity obtained from desolvation. From all evaluated xanthones, xan08, xan09, xan12 and xan12.1 (Figure 4D-F) presented significantly strong inhibition constants (Table 3). Unlike gentiopicroside, xanthones are able to establish a higher number of hydrogen bonds, including a network of shared bonds with the previously mentioned tyrosine side chains. The size of this hydrogen network may explain the differences between the strong and the not so strong inhibitors (Table 3). Position $\mathrm{R}_{1}$ seems to be the most important substitution for the formation of referred hydrogen network, which becomes particularly strong with a hydroxyl group, behaving both as a hydrogen bond acceptor and donor. Position $\mathrm{R}_{5}$ is also important 
since it interacts with the protein backbone, either as a donor (with carbonyl) or acceptor (with amide). Compound xan12 is able to establish an extra hydrogen bond with Trp286 (Figure 4F) which was retained in the binding mode of xan12.1, a derivative obtained by removing the methoxy group in position $\mathrm{R}_{2}$ (the arrow in Figure $4 \mathrm{~F}$ ), the strongest inhibitor found in our computational study.

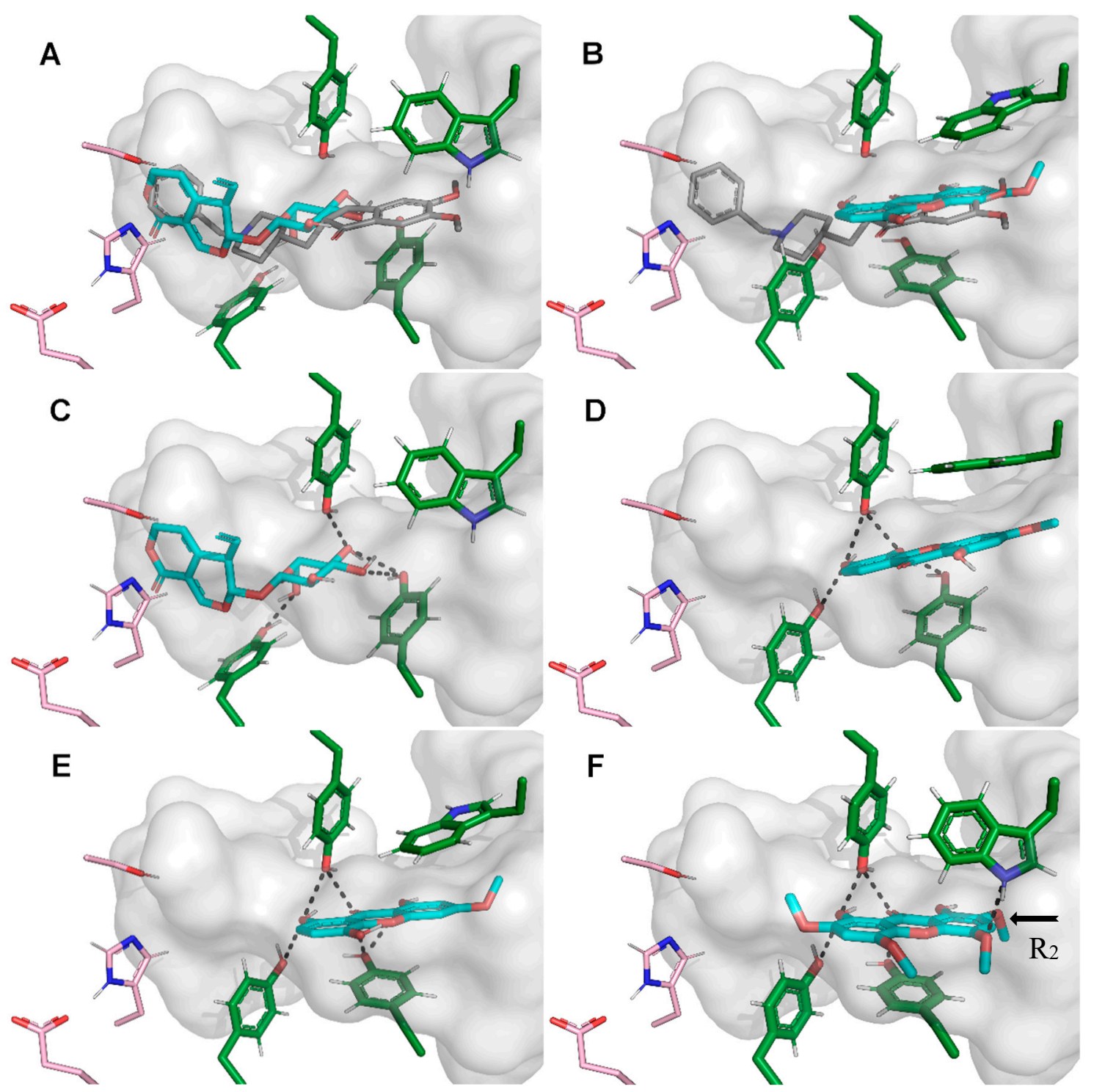

Figure 4. The lowest energy solutions from the docking calculations of gentiopicroside and the most active xanthones (cyan) in human AChE (green) are presented. Gentiopicroside (A) and xanthone 04 (B) are presented along with the X-ray structure of donepezil (PDB ID: 4EY7; [47]; dark grey) for a direct comparison. The interaction maps (black dashed lines) of gentiopicroside (C) and xanthones (D—xan03, E-xan04, F-xan09) in their best poses are also shown. The most active xanthone (xan09.1) differs from xan09 by removal of a methoxy group in the position $\mathrm{R}_{2}$ (highlighted with a black arrow-F). The catalytic residues of AChE are indicated with pink carbons. The active site pocket was calculated with hollow software [48] and represented as a gray surface. 
The docking studies that were performed showed that unlike gentiopicroside, xanthones which are also present in C. erythraea decoction, can be strong AChE inhibitors and their inhibition power depends on their $R_{x}$ group substitutions. Furthermore, in our work xan09 was identified as a good inhibitor, which is in good agreement with the experimentally measured IC $_{50}$ value of $18.5 \mu \mathrm{M}$ [49]. A series of rationally designed xanthones were created based on the best inhibitors found in this study and xan12.1 was identified as the strongest inhibitor we observed. However, stronger xanthone-based inhibitors with this template may still be undiscovered since we only grasped a fraction of all possible combinations of chemical groups and substitution positions. Therefore, our molecular docking protocol is particularly useful estimating the inhibition constant value range of a large number of xanthones, especially considering no specific xanthone identification was performed in the extracted fraction of C. erythraea decoction. Furthermore, our docking studies can help to foresee the location or position of the substituents in the xanthones identified in the extract as a tentative identification, according to the high activities determined.

\subsubsection{HMGR (3-hydroxy-3-methylglutaryl coenzyme A reductase) Inhibitory Activities and} Docking Studies

C. erythraea has also been reported to reduce high levels of blood cholesterol [4]. In the clinic, high levels of blood cholesterol are treated with statins, known to be cholesterol biosynthesis inhibitors. They act by inhibiting the activity of the regulator enzyme in the cholesterol biosynthetic pathway, 3-hydroxy-3-methyl-glutaryl-coenzyme A reductase (HMGR).

The inhibition of this enzyme was tested with $\mathrm{D}(48 \%)$ and $\mathrm{DM}_{\mathrm{f}}(27 \%)$, for the same concentration of $10 \mu \mathrm{g} / \mathrm{mL}$. These results suggest that the inhibitory potential of C. erythraea is mainly due to the monoterpenoids, which may reflect the potential of this plant in reducing cholesterol synthesis. The drug simvastatin has an $\mathrm{IC}_{50}$ of $0.2 \mu \mathrm{g} / \mathrm{mL}$ [40] which means it has a much stronger activity than the compounds present in C. erythraea. However, the drug is a pure compound and the decoction under study is a natural mixture of several compounds, some of which can have significant activities that are being masked in the mixture.

Studies of in silico docking report that swertiamarin, identified in this work, acts at the level of several enzymes and transcription factors involved in the metabolism of glucose and lipids, including in the inhibition of HMGR [50]. Peffley et al. [51] observed that monoterpenoids derived from the plant mevalonate pathway can control the synthesis of HMGR through a mechanism that appears to modulate the efficiency of mRNA translation.

In order to evaluate at molecular level and assign to which type of compounds present in the extract the high activity of HMGR inhibition could be ascribed, docking studies were also performed with gentiopicroside and all xanthones previously presented. The xanthone compound family has a modest binding affinity towards HMGR, featuring computed $\mathrm{K}_{\mathrm{i}}$ ranging from 54.8 to $184.8 \mu \mathrm{M}$ (Table 4). However, gentiopicroside seems to better fill the HMGR active site and to establish more hydrogen bond interactions than xanthone compounds, resulting in a stronger inhibition (calculated $K_{i}=19.9 \mu \mathrm{M}$ ). This protein has a very shallow active site and, unlike most statins (calculated $K_{i}=3.5 \mathrm{nM}$ for the example given), our compounds are only able to occupy a fraction of that site (Figure 5). Even though the tested compounds are of comparable size in comparison with stronger inhibitors such as piscidic acid, the latter being anionic is able to interact with a significant number of cationic residues (Lys735, Arg590, Lys692, Lys691), explaining its performance [45,52]. 
Table 4. Summary of all compounds used in the HMGR molecular docking calculations with their binding energies $\left(\Delta \mathrm{G}_{\mathrm{BIND}}\right)$ and inhibition constants $\left(\mathrm{K}_{\mathrm{i}}\right)$.

\begin{tabular}{ccc}
\hline Name & $\Delta \mathbf{G}_{\text {BIND }} \mathbf{( k c a l / m o l )}$ & $\mathbf{K}_{\mathbf{i}}(\boldsymbol{\mu M})$ \\
\hline xan01 & -5.7 & 70.6 \\
xan03 & -5.5 & 98.9 \\
xan04 (bellidifolin) & -5.3 & 129.6 \\
xan07 & -5.1 & 184.8 \\
xan13 & -5.6 & 78.1 \\
xan08 & -5.6 & 78.1 \\
xan05 & -5.5 & 94.1 \\
xan12 & -5.7 & 71.8 \\
xan10 & -5.2 & 150.9 \\
xan14 & -5.7 & 70.6 \\
xan15 & -5.3 & 129.6 \\
xan06 & -5.3 & 131.8 \\
xan02 & -5.8 & 54.8 \\
xan11 & -5.4 & 102.3 \\
xan09 & -5.6 & 74.3 \\
gentiopiocroside & -6.4 & 19.9 \\
statin & -11.5 & $3.5 \times 10^{-3}$ a) \\
\hline
\end{tabular}

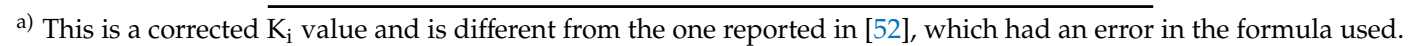

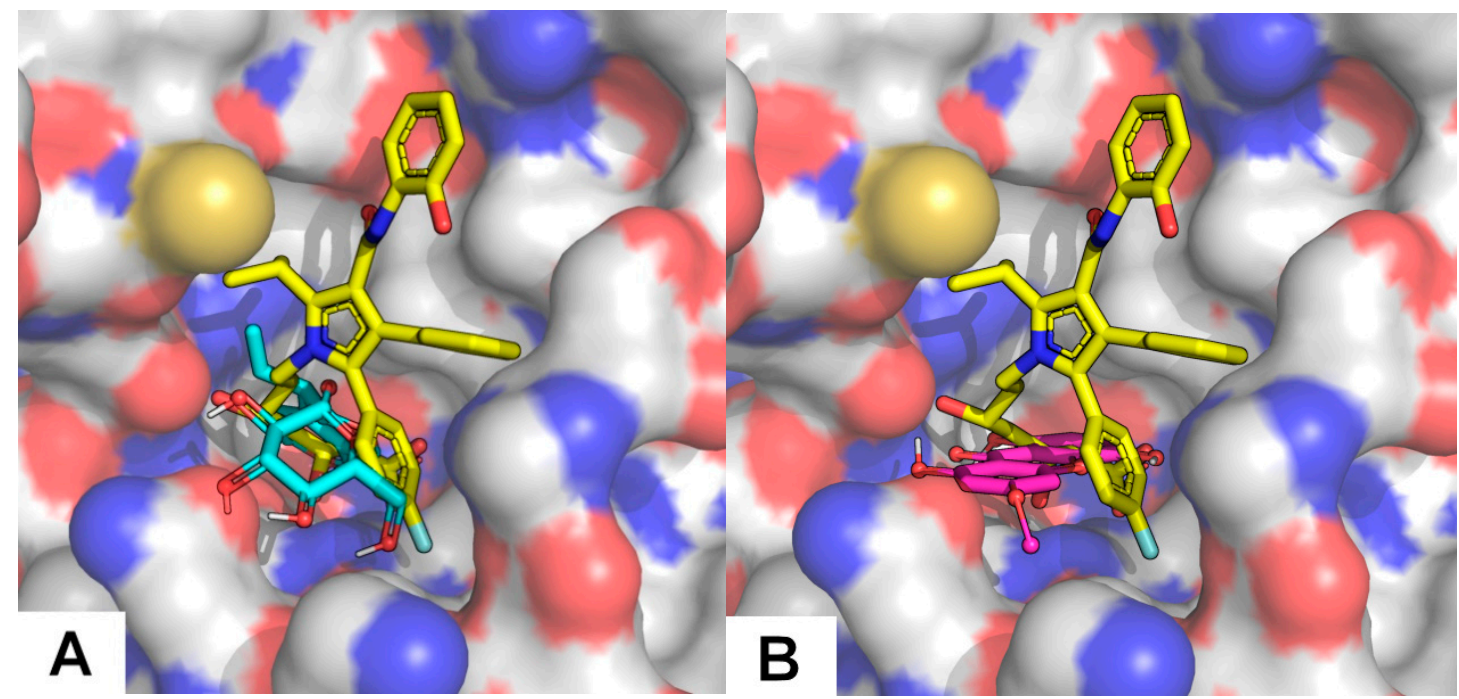

Figure 5. The lowest energy solutions from the docking calculations of a gentiopicroside (cyan-A) and xanthone 03 (pink-B) overlapped with the crystallographic structure of an atorvastatin derivative (yellow-1HW9); [53] in human HMGR (white carbons surface).

\section{Materials and Methods}

\subsection{Chemicals}

All chemicals were analytical grade. Methanol (MeOH), iron (II)-sulfate-7-hydrate and trichloroacetic acid were obtained from Riedel-de Haën ${ }^{\mathrm{TM}}$ (Seelze, Germany) and formic acid, water and acetonitrile (ACN) from Fisher Scientific, OptimaTM (Hampton, NH, USA). Trifluoroacetic acid (TFA), potassium dihydrogen phosphate, tris(hydroxymethyl)aminomethane (Tris) and sodium chloride were bought from Merck (Darmstadt, Germany). Ethanol 96\% was bought from Carlo Erba (Peypin, France), gentiopicroside from TransMIT (Hesse, Germany) and potassium chloride from Fluka (Seelze, Germany). Acetylcholinesterase (AChE), acetylcholine iodide (AChI), 5-5' -dithiobis (2-nitrobenzoic acid) (DTNB), HMG-CoA Reductase assay kit, gallic acid, 2,2-diphenyl-1-picrylhydrazyl 
(DPPH), butylated hydroxytoluene (BHT), quercetin, rutin and galantamine were obtained from Sigma (Barcelona, Spain). Magnesium chloride hexahydrate, thiobarbituric acid, hydrogen peroxide, sodium hydrogen phosphate and 1-butanol were bought to PanReac (Barcelona, Spain). Sodium hydroxide was obtained from JT Baker, UK and sodium nitroprusside and Griess reagent from VWR Chemicals PL.

\subsection{Plant and Decoction Preparation}

Aerial parts of C. erythraea Rafin. were bought in a local herbal shop (Celeiro-Dieta, Lisbon), dry, inside bags. The plant is caught at Global Positioning System (GPS) coordinates 39 $30^{\prime} 42^{\prime \prime} \mathrm{N}$, $8^{\circ} 47^{\prime} 58^{\prime \prime} \mathrm{O}$, Portugal, identified in the supplier and commercialized by a company certified for the commercialization of medicinal plants (ISO 9001/2015). A voucher specimen from the same species is kept in herbarium of the botanical garden with the number LISU253536. To obtain the aqueous extract a decoction of the plant was prepared, using $95 \mathrm{~g}$ of plant boiled in $950 \mathrm{~mL}$ of distilled water for $10 \mathrm{~min}$. The decoction (D) was filtered through Whatman grade paper number 1 and lyophilized with a yield of $19.3 \%$. Throughout the work, the extract was stored at $-80{ }^{\circ} \mathrm{C}$.

\subsection{Purification of Phenolic Compounds}

\subsubsection{Mucilages' Purification}

A purification of $\mathrm{D}$ was carried out withdrawing mucilages by precipitating the polymers according to the method of Henriques et al. [43]. Briefly, to a $10 \mathrm{mg} / \mathrm{mL}$ solution of the lyophilized decoction was added ethanol $96 \%$ in a ratio of 1:5. The mixture was kept in the ice for $8 \mathrm{~h}$ and centrifuged in an Eppendorf 5415D equipment, DE, at $3500 \times g$ for $30 \mathrm{~min}$. The supernatant free of mucilages was separated and kept for next experiments. The pellet was washed again with water and mucilages precipitated once more with ethanol as described previously. The second supernatant was mixed with the first and lyophilized. This fraction was designated as Decoction Mucilage Free $\left(\mathrm{DM}_{\mathrm{f}}\right)$ and it was stored at $-80{ }^{\circ} \mathrm{C}$ during the experimental work.

\subsubsection{Xanthones Fraction Collection}

The xanthones fraction (XF) was separated by HPLC-DAD by injecting repeatedly $25 \mu \mathrm{L}$ of $\mathrm{DM}_{\mathrm{f}}$ at $10 \mathrm{mg} / \mathrm{mL}$ and collecting fractions at retention time $11.5-30 \mathrm{~min}$.

\subsection{High-Performance Liquid Chromatography with Diode Array Detector (HPLC-DAD) Analysis}

The chromatographic analysis of the decoctions, the xanthones fraction collection and the enzymatic assay of 3-hydroxy-3-methyl-glutaryl-coenzyme A reductase (HMGR) were carried out in VWR-Hitachi Elite LaChrom®, equipped with a LiChroCARTßRP-18, $5 \mu \mathrm{m}, 250 \times 4 \mathrm{~mm}, 100 \AA$ column from Merck, autosampler L-2200, column oven L-2300 and diode array detector (DAD) L-2455. The software for data acquisition was EZChrom Eliteß, Hitachi Japan. For extract analysis $1 \mathrm{mg} / \mathrm{mL}$ of each extract was used and for XF isolation $10 \mathrm{mg} / \mathrm{mL}$ of $\mathrm{DM}_{\mathrm{f}}$ was used. The flow rate was $0.8 \mathrm{~mL} / \mathrm{min}$ and the detection was carried out between 200 and $500 \mathrm{~nm}$ using DAD. For decoction analysis and XF collection the mobile phase consisted of $0.05 \%(\mathrm{v} / \mathrm{v})$ of TFA in water (A) and acetonitrile (B). The elution conditions were as follows: $0 \mathrm{~min}, 92 \% \mathrm{~A}, 8 \% \mathrm{~B} ; 20 \mathrm{~min}, 82 \% \mathrm{~A}, 18 \% \mathrm{~B} ; 25 \mathrm{~min}, 45 \% \mathrm{~A}, 55 \% \mathrm{~B} ; 28 \mathrm{~min}$, $92 \% \mathrm{~A}, 8 \% \mathrm{~B}$ and $30 \mathrm{~min}, 92 \% \mathrm{~A}, 8 \% \mathrm{~B}$. For HMGR inhibition assay the mobile phase consisted of $\mathrm{KH}_{2} \mathrm{PO}_{4} 100 \mathrm{mM}$ in water (A) and $\mathrm{MeOH}(\mathrm{B})$, the gradient is described in Fale et al. [40]. The standard gentiopicroside was used to confirm the identification of the peak with higher intensity.

\subsection{Compound Identification by Liquid Chromatography-High Resolution Tandem Mass Spectrometry} (LC-MS/MS)

Samples were analyzed by liquid chromatography-high resolution tandem mass spectrometry (LC-MS-MS) using an Ultimate 3000 RSLCnano system (Thermo Fischer Scientific, Idstein, Germany) 
interfaced with a quadrupole time-of-flight (QqToF) Impact II mass spectrometer equipped with an electrospray source (Bruker Daltonics, Bremen, German).

Chromatography separation was carried out on a Kinetex $1.7 \mu \mathrm{m} \mathrm{C18} 100 \AA$, LC column $150 \times 2.1 \mathrm{~mm}$ (Phenomenex, California, USA), at flow rate of $150 \mu \mathrm{L} / \mathrm{min}$. Mobile phase consisted of $0.1 \%(\mathrm{v} / \mathrm{v})$ of acid formic in water $(\mathrm{A})$ and $0.1 \%(\mathrm{v} / \mathrm{v})$ of acid formic in acetonitrile (B), the elution conditions were described in André et al. [54]. The column and the sampler were maintained at $35^{\circ} \mathrm{C}$ and $10^{\circ} \mathrm{C}$, respectively.

The high-resolution mass spectra were acquired in the electrospray ionization (ESI) positive/negative modes. The optimized parameters were set as follows: ion spray voltage, $+4.5 /-2.5 \mathrm{kV}$; end plate offset, $500 \mathrm{~V}$, nebulizer gas $\left(\mathrm{N}_{2}\right), 2.8$ bars; dry gas $\left(\mathrm{N}_{2}\right), 8 \mathrm{~L} / \mathrm{min}$; dry heater, $200{ }^{\circ} \mathrm{C}$. Internal calibration was performed on the high-precision calibration mode (HPC) with a solution of sodium formate $10 \mathrm{mM}$ introduced to the ion source via a $20 \mu \mathrm{L}$ loop at the beginning of each analysis using a six-port valve. Acquisition was performed in full scan mode in the $m / z$ 50-1300 range, and in a data-depending MS/MS mode, with an acquisition of $3 \mathrm{~Hz}$ using a dynamic method with a fixed cycle time of $3 \mathrm{~s}$. Dynamic exclusion duration was $0.4 \mathrm{~min}$. The acquired data were processed by DataAnalysis 4.1 software (Bruker Daltoniks).

\subsection{Total Phenol Content Quantification}

Total phenol content was measured spectrophotometrically, at $760 \mathrm{~nm}$, using Folin-Ciocalteu reagent as described in Henriques et al. [43], using gallic acid as a standard (10-500 $\mu \mathrm{g} / \mathrm{mL})$. The samples analyzed were $\mathrm{D}, \mathrm{DM}_{\mathrm{f}}$ and $\mathrm{XF}$. The concentration of total phenols was determined as $\mu \mathrm{g}$ of gallic acid equivalents per mg of dry extract as the mean of three replicates.

\subsection{Antioxidant Activity Determination}

\subsubsection{DPPH Radical Scavenging Activity}

The radical scavenging activity of C. erythraea was evaluated by using DPPH method described by Falé et al. [55]. In short, $10 \mu \mathrm{L}$ of the sample solution was added at a concentration of $5 \mathrm{mg} / \mathrm{mL}$ to $1 \mathrm{~mL}$ of the DPPH solution $(0.002 \%$ in $\mathrm{MeOH})$, the solutions were incubated at room temperature for $30 \mathrm{~min}$ and then the absorbance of the different samples was measured on the microplate reader at $517 \mathrm{~nm}$ against a blank. BHT, rutin and quercetin were used as standards and for these compounds the concentration value to accomplish an extinction of absorption of $50 \%\left(\mathrm{EC}_{50}\right)$ was determined. All assays were performed in triplicate and are presented as mean and standard deviation associated to the measurements. In order to calculate the percentage of antioxidant activity, the following expression was used:

$$
\text { AA }(\%)=100 \times\left(\mathrm{A}_{\text {test }}-\left(\mathrm{A}_{\text {sample }} / \mathrm{A}_{\text {test }}\right)\right)
$$

In which AA (\%) corresponds to the percentage of antioxidant activity, $\mathrm{A}_{\text {sample }}$ refers to the absorbance of each sample and $A_{\text {test }}$ to the absorbance of the control solution.

\subsubsection{Lipoperoxidation Inhibition}

Inhibition of lipid oxidation was evaluated by the thiobarbituric acid reactive substances (TBARS) method described by Tokur et al. [56] with minor optimizations, being the values presented as the mean of three independent tests and the standard deviation associated to the measurements. In this assay, the commercial standard used was $\mathrm{BHT}$ and its $\mathrm{EC}_{50}$ determined. The percentage inhibition of lipid peroxidation was calculated according to Equation (1).

\subsubsection{Nitric Oxide Radical Scavenging Activity}

Nitric oxide radical scavenging assay was performed in triplicate according to the modified method described by Sakat et al. [57] with some adaptations described in [43]. The values are presented 
as the mean of three independent tests and the standard deviation associated to the measurements. The percentage of inhibition was calculated according to Equation (1) for D and for the standard rutin.

\subsection{Determination of Enzymatic Activity}

\subsubsection{Acetylcholinesterase Inhibitory Activity}

AChE inhibition was performed in triplicate as described by Falé et al. [55]. Succinctly, to calculate the enzyme activity without inhibitor (100\% activity), $325 \mu \mathrm{L}$ of $50 \mathrm{mM}$ Tris buffer pH $8,100 \mu \mathrm{L}$ of Milli-Q water and $25 \mu \mathrm{L}$ of AChE solution $(1.33 \mathrm{U} / \mathrm{mL})$ were mixed in a cuvette and incubated, at $25^{\circ} \mathrm{C}$, for $15 \mathrm{~min}$. Next $75 \mu \mathrm{L}$ of AChI $(0.33 \mathrm{mg} / \mathrm{mL}), 475 \mu \mathrm{L}$ of DTNB $(1.2 \mathrm{mg} / \mathrm{mL}$ of $50 \mathrm{mM}$ Tris buffer pH 8 containing $0.1 \mathrm{M} \mathrm{NaCl}$ and $0.02 \mathrm{M} \mathrm{MgCl}_{2}$ ) were added and the absorbance was read on the spectrophotometer Schimadzu UV-160A, Japan, at $405 \mathrm{~nm}$, for 4 min with 10 second intervals and the initial velocity was calculated. The same procedure was carried out with the different samples, but instead of adding $100 \mu \mathrm{L}$ of Milli-Q water, the same volume of a solution of the various samples, at $5 \mathrm{mg} / \mathrm{mL}$, was added. In this assay, the commercial standard used was galantamine.

\subsubsection{HMGR Inhibitory Activity}

To determine the inhibition of the enzymatic activity of HMGR, the oxidation of nicotinamide adenine dinucleotide phosphate hydrate (NADPH) was evaluated in triplicate according to the method described by Mozzicafreddo et al. [58] with minor modifications. First, in order to calculate maximum enzyme activity (100\%), the kit indications were followed. Then, aliquots were removed at 0,1, 2, 4 and $6 \mathrm{~min}$, the reaction was stopped by adding $\mathrm{MeOH}$ to a final volume of $50 \%$ and the samples were analyzed by HPLC-DAD using VWR-Hitachi Elite LaChrom $®$, referred in 4.4. The decrease in the absorbance of the NADPH was monitored at $340 \mathrm{~nm}$, evaluating the decrease of the peak area over time, which allowed to make a linear regression and to obtain the reaction velocity.

\subsection{Computational Methods}

The AChE and HMGR structures (PDB IDs: AChE-1B41; HMG-3CCT) were processed as previously described [45]. The studied ligands were: gentiopicroside and a series of xanthones derivatives with combinations of hydroxyl and methoxy groups. The geometry optimizations were performed with Gaussian 09 [59] using B3LYP theory level and the 6-31G(d,p) basis set. The optimized conformations were used in the docking calculations with AutoDock suite version 4.2.6 [60]. In these calculations, AChE was treated as a rigid body with four partially flexible residues (Tyr124, Trp286, Tyr337 and Tyr341) in the enzyme active site. The flexibility of the selected residues between the $C_{\alpha}$ and $\mathrm{C}_{\gamma}$ carbons (two torsions per residue), as well as all possible torsions in the ligands, was set with AutoDock Tools version 1.5.6 [60,61].

The search space of possible interactions between ligand and receptor within the previously described [45] interaction region was explored by the AutoDock Lamarckian Genetic (LGA) algorithm. Electrostatic interactions were computed using the dielectric function of Mehler and Solmajer while hydrogen bonding terms and Van der Waals were computed using AutoDock parameters [62].

The 1250 LGA runs were performed using standard AutoDock parameters except for the number of individuals in the population (100) and the maximum number of energy evaluations $\left(8 \times 10^{6}\right)$. In the clustering procedure a root mean squared tolerance of 1.0-1.5 $\AA$ was used on the heavy atoms of the flexible region. The representative binding modes selected were the lowest energy conformations belonging to the most populated clusters.

\subsection{Statistical Analysis}

The results are expressed as mean \pm standard deviation. The statistical differences between groups, using a probability level of $p \leq 0.05$, were assessed by one-way variance analysis (ANOVA), available in Microsoft Office $2013^{\circledR}$ software. Correlations were calculated using a regression line between the 
antioxidant activity measured with DPPH test and inhibitory activity of acetylcholinesterase with the total phenolic content in the fractions collected.

\section{Conclusions}

C. erythraea when prepared as a decoction has the ability to inhibit both AChE and HMGR activity. It also has antioxidant activity due to the presence of xanthones molecules. The docking studies helped us to understand at the molecular level and attribute which activity are due to which type of compound in the aqueous extraction. A large number of xanthones are good AChE inhibitors while secoiridoids like gentiopicroside can inhibit HMGR. This top-down approach helped us to understand how such a mixture of compounds present in the decoction can act in different fronts to produce ethno-pharmacological effects as described by people that consume this medicinal beverage.

Author Contributions: L.G., P.B.P.S.R., and A.R., formal analysis and investigation; M.M. software validation; M.M. and M.L.S., conceptualization and supervision; M.M. and M.L.S. methodology; M.L.S. resources; L.G., P.B.P.S.R., A.R., R.P., M.M. writing—original draft preparation; R.P., M.M. and M.L.S. writing—review and editing, L.G., P.B.P.S.R. and M.M.: visualization, M.L.S. supervision: M.L.S. project administration and funding acquisition.

Funding: This research was supported by the Portuguese Foundation for Science and Technology, FCT, through the Research Unit grant UID/MULTI/04046/2019 to BioISI; FCT project PTDC/BIA-BQM/28355/2017; MM and PR acknowledge grants CEECIND/02300/2017 and SFRH/BD/136226/2018, respectively.

Acknowledgments: We acknowledge Clarinda Paixão for the plant identification.

Conflicts of Interest: The authors declare that there are no conflicts of interest.

\section{References}

1. Cunha, A.P.; Silva, A.P.; Roque, O. Plantas e Produtos Vegetais em Fitoterapia; Fundação Calouste Gulbenkian: Lisbon, Portugal, 2003; pp. 216-334. ISBN 978-972-31-1435-5.

2. Tuluce, Y.; Ozkol, H.; Koyuncu, I.; Ine, H. Gastroprotective effect of small centaury (Centaurium erythraea L.) on aspirin-induced gastric damage in rats. Toxicol. Ind. Health 2011, 27, 760-768. [CrossRef] [PubMed]

3. Benabdelkrim, I.; Rachid, A.; Zaid, A.; Cherrah, Y.; Alaoui, T.; Jean-Louis, G.; El Badaoui, K.K. Effect of aqueous extract from Erythrea Centaurium in Merione shawi. Int. J. Diabetol. Vasc. Dis. Res. 2014, 2, 71-75.

4. EMA European Medicines Agency. Assessment Report on Centaurium Erythraea Rafn. s.l., Herba; EMA: London, UK, 2015.

5. Deng, Y.; Wang, L.; Yang, Y.; Sun, W.; Xie, R.; Liu, X.; Wang, Q. In vitro inhibition and induction of human liver cytochrome P450 enzymes by gentiopicroside: Potent effect on CYP2A6. Drug Metab. Pharmacokinet. 2013, 28, 339-344. [CrossRef] [PubMed]

6. Mirzaee, F.; Hosseini, A.; Jouybari, H.B.; Davoodi, A.; Azadbakht, M. Medicinal, biological and phytochemical properties of Gentiana species. J. Tradit. Complement. Med. 2017, 7, 400-408. [CrossRef] [PubMed]

7. Lonkar, P.; Dedon, P.C. Reactive species and DNA damage in chronic inflammation: Reconciling chemical mechanisms and biological fates. Int. J. Cancer 2011, 128, 1999-2009. [CrossRef] [PubMed]

8. Shan, T.; Ma, Q.; Guo, K.; Liu, J.; Li, W.; Wang, F.; Wu, E. Xanthones from mangosteen extracts as natural chemopreventive agents: Potential anticancer drugs. Curr. Mol. Med. 2011, 11, 666-677. [CrossRef]

9. Roleira, F.M.F.; Tavares-Da-Silva, E.J.; Varela, C.L.; Costa, S.C.; Silva, T.; Garrido, J.; Borges, F. Plant derived and dietary phenolic antioxidants: Anticancer properties. Food Chem. 2015, 183, 235-258. [CrossRef]

10. Pisoschi, A.M.; Pop, A. The role of antioxidants in the chemistry of oxidative stress: A review. Eur. J. Med. Chem. 2015, 97, 55-74. [CrossRef]

11. Guan, G.; Lan, S. Implications of antioxidant systems in inflammatory bowel disease. Biomed Res. Int. 2018, 2018, 1-7. [CrossRef]

12. Kumarasamy, Y.; Nahar, L.; Cox, P.J.; Jaspars, M.; Sarker, S.D. Bioactivity of secoiridoid glycosides from Centaurium erythraea. Phytomedicine 2003, 10, 344-347. [CrossRef]

13. Berkan, T.; Üstünes, L.; Lermioglu, F.; Özer, A. Antiinflammatory, Analgesic, and Antipyretic Effects of an Aqueous Extract of Erythraea centaurium. Planta Med. 1991, 57, 34-37. [CrossRef] [PubMed]

14. Tahraoui, A.; Israili, Z.H.; Lyoussi, B. Acute and sub-chronic toxicity of a lyophilised aqueous extract of Centaurium erythraea in rodents. J. Ethnopharmacol. 2010, 132, 48-55. [CrossRef] [PubMed] 
15. Aberham, A.; Pieri, V.; Croom, E.M.; Ellmerer, E.; Stuppner, H. Analysis of iridoids, secoiridoids and xanthones in Centaurium erythraea, Frasera caroliniensis and Gentiana lutea using LC-MS and RP-HPLC. J. Pharm. Biomed Anal. 2011, 54, 517-525. [CrossRef] [PubMed]

16. Valentão, P.; Fernandes, E.; Carvalho, F.; Andrade, P.B.; Seabra, R.M.; Bastos, M.L. Antioxidant activity of Centaurium erythraea infusion evidenced by its superoxide radical scavenging and xanthine oxidase inhibitory activity. J. Agric. Food Chem. 2001, 49, 3476-3479. [CrossRef] [PubMed]

17. Molina, M.A.R.; Bah, M.; Rojas, J.I.; Gutiérrez, D.M. Smooth muscle relaxing activity of gentiopicroside isolated from Gentiana spathacea. Planta Med. 2000, 66, 765-767.

18. Chen, L.; Liu, J.; Zhang, X.; Guo, Y.; Xu, Z.; Cao, W.; Sun, X.; Sun, W.; Zhao, M.G. Down-regulation of NR2B receptors partially contributes to analgesic effects of gentiopicroside in persistent inflammatory pain. Neuropharmacology 2008, 54, 1175-1181. [CrossRef]

19. Senol, F.S.; Yagci Tuzun, C.; Toker, G.; Orhan, I.E. An in vitro perspective to cholinesterase inhibitory and antioxidant activity of five Gentiana species and Gentianella caucasea. Int. J. Food Sci. Nutr. 2012, 63, 802-812. [CrossRef]

20. Lian, L.H.; Wu, Y.L.; Wan, Y.; Li, X.; Xie, W.X.; Nan, J.X. Anti-apoptotic activity of gentiopicroside in d-galactosamine/lipopolysaccharide-induced murine fulminant hepatic failure. Chem. Biol. Interact. 2010, 188, 127-133. [CrossRef]

21. Mustafayeva, K.; Di Giorgio, C.; Elias, R.; Kerimov, Y.; Ollivier, E.; De Méo, M. DNA-damaging, mutagenic, and clastogenic activities of gentiopicroside isolated from Cephalaria kotschyi roots. J. Nat. Prod. 2010, 73, 99-103. [CrossRef]

22. Ruan, M.; Yu, B.; Xu, L.; Zhang, L.; Long, J.; Shen, X. Attenuation of stress-induced gastrointestinal motility disorder by gentiopicroside, from Gentiana macrophylla Pall. Fitoterapia 2015, 103, 265-276. [CrossRef]

23. Stefkov, G.; Miova, B.; Dinevska-Kjovkarovska, S.; Stanoeva, J.P.; Stefova, M.; Petrusevska, G.; Kulevanova, S. Chemical characterization of Centaurium erythrea L. and its effects on carbohydrate and lipid metabolism in experimental diabetes. J. Ethnopharmacol. 2014, 152, 71-77. [CrossRef] [PubMed]

24. Bisht, V.K.; Negi, J.S.; Joshi, G.P.; Singh, P.; Rawat, M.S.M. Naturally occurring xanthones: Chemistry and biology. J. Appl. Chem. 2013, 2013, 1-9.

25. Hassan, N.K.N.C.; Taher, M.; Susanti, D. Phytochemical constituents and pharmacological properties of Garcinia xanthochymus-A review. Biomed Pharmacother. 2018, 106, 1378-1389. [CrossRef] [PubMed]

26. Valenzuela, I.M.P.; Mohammed, A. Acetylcholinesterase mobility and stability at the neuromuscular junction of living mice. Mol. Biol. Cell 2007, 18, 2904-2911. [CrossRef] [PubMed]

27. England, P.M. Bridging the gaps between synapses, circuits, and behavior. Chem. Biol. 2010, 17, 607-615. [CrossRef]

28. Bharucha, A.E.; Low, P.; Camilleri, M.; Veil, E.; Burton, D.; Kudva, Y.; Shah, P.; Gehrking, T.; Zinsmeister, A.R. A randomised controlled study of the effect of cholinesterase inhibition on colon function in patients with diabetes mellitus and constipation. Gut 2013, 62, 708-715. [CrossRef]

29. Jarvie, E.M.; Cellek, S.; Sanger, G.J. Potentiation by cholinesterase inhibitors of cholinergic activity in rat isolated stomach and colon. Pharmacol. Res. 2008, 58, 297-301. [CrossRef]

30. Nagahama, K.; Matsunaga, Y.; Kawachi, M.; Ito, K.; Tanaka, T.; Hori, Y.; Oka, H.; Takei, M. Acotiamide, a new orally active acetylcholinesterase inhibitor, stimulates gastrointestinal motor activity in conscious dogs. Neurogastroenterol. Motil. 2012, 24, 566-574. [CrossRef]

31. Zhang, X.; Song, J.; Shi, X.; Miao, S.; Li, Y.; Wen, A. Absorption and metabolism characteristics of rutin in Caco-2 cells. Sci. World J. 2013, 2013, 1-8. [CrossRef]

32. García-Ayllón, M.S.; Small, D.; Avila, J.; Sáez-Valero, J. Revisiting the role of acetylcholinesterase in Alzheimer's disease: Cross-talk with P-tau and $\beta$-amyloid. Front. Mol. Neurosci. 2011, 4, 1-9. [CrossRef]

33. Singh, N.; Tamariz, J.; Chamorro, G.; Medina-Franco, J.L. Inhibitors of HMG-CoA reductase: Current and future prospects. Mini-Rev. Med. Chem. 2009, 9, 1272-1283. [CrossRef] [PubMed]

34. Stancu, C.; Sima, A. Statins: Mechanism of action and effects. J. Cell. Mol. Med. 2001, 5, 378-387. [CrossRef] [PubMed]

35. Jensen, S.R.; Schripsema, J. Chemotaxonomy and pharmacology of Gentianaceae. In Gentianaceae Systematics and Natural History; Cambridge University Press: Cambridge, UK, 2002; Volume 4, pp. 573-631.

36. Alam, M.N.; Bristi, N.J.; Rafiquzzaman, M. Review on in vivo and in vitro methods evaluation of antioxidant activity. Saudi Pharm. J. 2013, 21, 143-152. [CrossRef] [PubMed] 
37. Foti, M.C. Use and abuse of the DPPH radical. J. Agric. Food Chem. 2015, 63, 8765-8776. [CrossRef] [PubMed]

38. Kiliç, I.; Yesiloglu, Y.; Bayrak, Y. Investigation on the antioxidant activity of roots and stem of Colchicum turcicum L. Asian J. Chem. 2014, 26, 5-9. [CrossRef]

39. Attanayake, A.P.; Jayatilaka, K.A.P.W. Evaluation of antioxidant properties of 20 medicinal plant extracts traditionally used in Ayurvedic medicine in Sri Lanka. Indian J. Tradit. Knowl. 2016, 15, 50-56.

40. Falé, P.L.; Ferreira, C.; Maruzzella, F.; Helena Florêncio, M.; Frazão, F.N.; Serralheiro, M.L.M. Evaluation of cholesterol absorption and biosynthesis by decoctions of Annona cherimola leaves. J. Ethnopharmacol. 2013, 150, 718-723. [CrossRef]

41. Blanco-Ayala, T.; Lugo-Huitrón, R.; Serrano-López, E.M.; Reyes-Chilpa, R.; Rangel-López, E.; Pineda, B.; Medina-Campos, O.N.; Sánchez-Chapul, L.; Pinzón, E.; Cristina, T.S.; et al. Antioxidant properties of xanthones from Calophyllum brasiliense: Prevention of oxidative damage induced by $\mathrm{FeSO}_{4}$. BMC Complement. Altern. Med. 2013, 13, 1-15. [CrossRef]

42. Pacher, P.; Beckman, J.S.; Liaudet, L. Nitric oxide and peroxynitrite in health and disease. Physiol. Rev. 2007, 87, 315-424. [CrossRef]

43. Henriques, J.; Ribeiro, M.J.; Falé, P.L.; Pacheco, R.; Ascensão, L.; Florêncio, M.H.; Serralheiro, M.L.M. Valorization of kiwifruit production: Leaves of the pruning branches of Actinidia deliciosa as a promising source of polyphenols. Eur. Food Res. Technol. 2017, 243, 1343-1353. [CrossRef]

44. Urbain, A.; Marston, A.; Queiroz, E.F.; Ndjoko, K.; Hostettmann, K. Xanthones from Gentiana campestris as new acetylcholinesterase inhibitors. Planta Med. 2004, 70, 1011-1014. [CrossRef] [PubMed]

45. Silva, L.; Rodrigues, A.M.; Ciriani, M.; Falé, P.L.V.; Teixeira, V.; Madeira, P.; Machuqueiro, M.; Pacheco, R.; Florêncio, M.H.; Ascensão, L.; et al. Antiacetylcholinesterase activity and docking studies with chlorogenic acid, cynarin and arzanol from Helichrysum stoechas (Lamiaceae). Med. Chem. Res. 2017, 26, 2942-2950. [CrossRef]

46. Valentão, P.; Fernandes, E.; Carvalho, F.; Andrade, P.B.; Seabra, R.M.; Bastos, M.L. Antioxidative properties of cardoon (Cynara cardunculus L.) infusion against superoxide radical, hydroxyl radical, and hypochlorous acid. J. Agric. Food Chem. 2002, 50, 4989-4993. [CrossRef] [PubMed]

47. Valentão, P.; Areias, F.; Amaral, J.; Andrade, P.; Seabra, R. Tetraoxygenated xanthones from Centaurium erythraea. Nat. Prod. Lett. 2000, 14, 319-323. [CrossRef]

48. Cheung, J.; Rudolph, M.J.; Burshteyn, F.; Cassidy, M.S.; Gary, E.N.; Love, J.; Franklin, M.C.; Height, J.J. Structures of human acetylcholinesterase in complex with pharmacologically important ligands. J. Med. Chem. 2012, 55, 10282-10286. [CrossRef]

49. Nag, G.; Das, S.; Das, S.; Mandal, S.; De, B. Antioxidant, anti-acetylcholinesterase and anti-glycosidase properties of three species of Swertia, their xanthones and amarogentin: A comparative study. Pharmacogn. J. 2015, 7, 117-123. [CrossRef]

50. Bhatt, J.; Vaidya, H.; Khanna, V.; Patel, N.; Goyal, R. In silico docking studies for designing potent anti-diabetic derivatives of swertiamarin with enzyme HMG COA reductase. Mol. Cytogenet. 2014, 7, 97. [CrossRef]

51. Peffley, D.M.; Gayen, A.K. Plant-derived monoterpenes suppress hamster kidney cell 3-hydroxy-3methylglutaryl coenzyme A reductase synthesis at the post- transcriptional level. J. Nutr. 2003, 133, 38-44. [CrossRef]

52. Ressaissi, A.; Attia, N.; Falé, P.L.; Pacheco, R.; Victor, B.L.; Machuqueiro, M.; Serralheiro, M.L.M. Isorhamnetin derivatives and piscidic acid for hypercholesterolemia: Cholesterol permeability, HMG-CoA reductase inhibition, and docking studies. Arch. Pharm. Res. 2017, 40, 1278-1286. [CrossRef]

53. Sarver, R.W.; Bills, E.; Bolton, G.; Bratton, L.D.; Caspers, N.L.; Dunbar, J.B.; Harris, M.S.; Hutchings, R.H.; Kennedy, R.M.; Larsen, S.D.; et al. Thermodynamic and structure guided design of statin based inhibitors of 3-hydroxy-3-methylglutaryl coenzyme A reductase. J. Med. Chem. 2008, 51, 3804-3813. [CrossRef]

54. André, R.; Catarro, J.; Freitas, D.; Pacheco, R.; Oliveira, M.C.; Serralheiro, M.L.; Falé, P.L. Action of euptox A from Ageratina adenophora juice on human cell lines: A top-down study using FTIR spectroscopy and protein profiling. Toxicol. Vitr. 2019, 57, 217-225. [CrossRef] [PubMed]

55. Falé, P.L.; Ferreira, C.; Rodrigues, A.M.; Cleto, P.; Madeira, P.J.A.; Florêncio, M.H.; Frazão, F.N.; Serralheiro, M.L.M. Antioxidant and anti-acetylcholinesterase activity of commercially available medicinal infusions after in vitro gastrointestinal digestion. J. Med. Plants Res. 2013, 7, 1370-1378.

56. Tokur, B.; Korkmaz, K. The effects of an iron-catalyzed oxidation system on lipids and proteins of dark muscle fish. Food Chem. 2007, 104, 754-760. [CrossRef] 
57. Sakat, S.S.; Juvekar, A.R.; Gambhire, M.N. In-vitro antioxidant and anti-inflammatory activity of methanol extract of Oxalis corniculata linn. Int. J. Pharm. Pharm. Sci. 2010, 2, 146-155.

58. Mozzicafreddo, M.; Cuccioloni, M.; Eleuteri, A.M.; Angeletti, M. Rapid reverse phase-HPLC assay of HMG-CoA reductase activity. J. Lipid Res. 2010, 51, 2460-2463. [CrossRef] [PubMed]

59. Frisch, M.J.; Trucks, G.W.; Schlegel, H.B.; Scuseria, G.E.; Robb, M.A.; Cheeseman, J.R.; Scalmani, G.; Barone, V.; Mennucci, B.; Petersson, G.A.; et al. Gaussian 09, Revision D.01, Gaussian. Inc.: Wallingford, CT, USA, 2009.

60. Morris, G.; Huey, R.; Lindstrom, W.; Sanner, M.; Belew, R.; Goodsell, D.; Olson, A. AutoDock4 and AutoDockTools4: Automated docking with selective receptor flexibility. J. Comput. Chem. 2009, 30, 2785-2791. [CrossRef] [PubMed]

61. Harris, R.; Olson, A.; Goodsell, D. Automated prediction of ligand-binding sites in proteins. Proteins Struct. Funct. Bioinforma. 2008, 70, 1506-1517. [CrossRef]

62. Mehler, E.L.; Solmajer, T. Electrostatic effects in proteins: Comparison of dielectric and charge models. Protein Eng. 1991, 4, 903-910. [CrossRef]

Sample Availability: Samples of the compounds and water extracts are available from the authors.

(C) 2019 by the authors. Licensee MDPI, Basel, Switzerland. This article is an open access article distributed under the terms and conditions of the Creative Commons Attribution (CC BY) license (http://creativecommons.org/licenses/by/4.0/). 